\title{
Local Approach to Fracture Applied to Reactor Pressure Vessel: Synthesis of a Cooperative Programme Between EDF, CEA, Framatome and AEA
}

\author{
D. Moinereau, J.M. Frund, J. Brochard*, B. Marini*, P. Joly**, D. Guichard**, S. Bhandari**, \\ A. Sherry***, D.J. Sanderson***, C. France*** and D.P.G. Lidbury*** \\ EDF/DERMTC, Centre des Renardières, BP. 1, Route de Sens-Ecuelles, 77250 Moret-sur-Loing, France \\ * CEA/CEREM/SRMA, CEA Saclay, 91191 Gif-sur-Yvette, France \\ ** FRAMATOME, Département Matériaux BAL 721A, Tour Framatome, 92084 Paris-la-Défense \\ cedex 16, France \\ *** AEA Technology place, 329 Harwell Didcot, Oxford OX11, U.K.
}

\begin{abstract}
A cooperative research programme in the field of the local approach to cleavage fracture applied to reactor pressure vessels is conducted between EDF, CEA, Framatome and AEA Technology. The purpose of such a programme is to have a better knowledge of this approach for RPV fracture mechanics integrity assessments regarding the risk of brittle fracture. This programme includes both an experimental part conducted by several laboratories in order to identify $\mathrm{m}$ and $\sigma_{\mathrm{u}}$ parameters of Beremin model on a A508 $\mathrm{Cl} 3$ steel, and numerous numerical computations of specimens and structures. Finite element programs are compared on some reference calculations in order to validate local approach to fracture postprocessors. The capability of Beremin model to explain the shallow flaw effect in cleavage fracture is finally discussed.
\end{abstract}

\section{1 - OBJECTIVE}

In order to evaluate the capability of local approach to cleavage fracture (Beremin model) to be used in reactor pressure vessel structural integrity assessments regarding brittle fracture, an extensive research programme has been conducted between EDF, CEA, Framatome and AEA Technology including both experimental and numerical studies.

The identification of Beremin model parameters on a $\mathrm{A} 508 \mathrm{Cl} 3$ steel is examined by performing numerous mechanical tests on axisymmetrical notched tensile specimens at several temperatures. The capabilities of several finite element programmes are compared in the field of local approach to cleavage fracture on some reference. Finally, the shallow flaw effect in cleavage fracture is discussed including numerical calculations and experimental applications.

\section{2 - THE LOCAL APPROACH TO CLEAVAGE FRACTURE}

The local approach to cleavage fracture (Beremin model or Weibull model), developed by F. Mudry, is based on the weakest link theory and the use of Weibull statistics $(1)(2)(3)$. The model, now well known, is based on the elastic - plastic computation of a structure, without coupling between plasticity and damage, and on the use of a damage criterion computed from the stress - strain field at the crack tip.

The probability $P$ of initiating cleavage fracture is expressed as $\mathbf{P}=\mathbf{1}-\exp \left(-\left(\sigma_{w} / \sigma_{u}\right)^{\mathrm{m}}\right)$. $\sigma_{w}$ is the "Weibull stress " and characterizes the mechanical conditions exerted at the crack tip relevant to the risk of initiating cleavage fracture : $\sigma_{\mathbf{w}}=\left(\Sigma_{\mathbf{j}} \sigma_{\mathbf{1}} \mathbf{m}\left(\mathbf{V}_{\mathbf{j}} / \mathbf{V}_{0}\right)\right)^{(\mathbf{1} / \mathbf{m})}$ 
$\sigma_{1 j}$ is the value of maximum principal stress in the finite element cell, number $\mathrm{j}, \mathrm{V}_{\mathrm{j}}$ is the volume of the mesh element and $V_{0}$ the volume of the material cell. The integration is made on the plastic zone ahead of the crack tip.

The model is defined by two parameters $\mathrm{m}$ and $\sigma_{\mathrm{u}} . \mathrm{m}$ is the Weibull parameter and characterizes the scatter in cleavage fracture. $\sigma_{u}$ is defined as the intrinsic cleavage stress of the material and characterizes the resistance to cleavage fracture. Both parameters, which are assumed to be characteristics of the material, are usually determined through tests on axisymmetrical notched tensile specimens and numerical calculations.

\section{3 - IDENTIFICATION OF m, $\sigma_{u}$ BEREMIN MODEL PARAMETERS ON A A508 Cl3 STEEL}

\subsection{Objectives}

The objectives of this action were to develop a validated procedure to identify the Beremin model parameters which may be used with confidence, and to evaluate a set of parameters usable for the analysis of behaviour of pressure vessel steel. The effect of temperature on the model parameters in particular is examined.

\subsection{Studied material and specimens sampling}

The studied material is a low alloy steel of $\mathrm{A} 508 \mathrm{Cl} 3$ type (table 1$)\left(\mathrm{RT}_{\mathrm{NDT}}=-40^{\circ} \mathrm{C}\right.$ ). Specimens were taken in a block sectioned from part of a ring. The block was subjected to a heat treatment for mechanical properties and a post-weld heat treatment.

One hundred and twenty notched tensile specimens (figure 1) were machined from the block, with the tensile axis oriented in the transverse direction of the material.

\subsection{Mechanical tests on notched specimens}

Tests on notched tensile specimens were performed by three laboratories according an experimental procedure derived from the ESIS round robin (4). Specimens were tested using servo - hydraulic machines operating under displacement or extensometer control. The average strain rate was $10^{-3} \mathrm{~s}^{-1}\left(-5.10^{-3} \mathrm{~mm} \cdot \mathrm{s}^{-1}\right.$ for the diametral contraction rate). Applied load and diametral contraction were monitored during the test up to the point of specimen failure. Following the tests, the minimal diameter was measured in both transverse and normal directions to provide an average diameter at fracture.

Experimental tests were performed at three test temperatures $\left(-170{ }^{\circ} \mathrm{C},-130{ }^{\circ} \mathrm{C},-100{ }^{\circ} \mathrm{C}\right)$ in order to study the effect of temperature on $\mathrm{m}$ and $\sigma_{\mathrm{u}}$ parameters. Table 2 presents the number of specimens tested at each temperature. Laboratories 1 and 2 performed tests using a displacement control, the control of tests performed by the laboratory 3 was assured by a diametral extensometer.

\subsection{Experimental results}

The laboratory 1 used post - mortem measures of diametral contraction for the determination of mean stresses and mean strains at fracture whilst laboratories 2 and 3 used the measure of diametral extensometer at the moment of fracture.

Figure 2 shows the variation of mean stress at fracture $\sigma_{\mathrm{F}}$ according to mean strain at fracture $\varepsilon \mathrm{F}$. We can see a large scatter band for results obtained at $-130{ }^{\circ} \mathrm{C}$ and $-100{ }^{\circ} \mathrm{C}$. For all test temperatures, levels of strain are inferior at $5 \%$ (temperature of $-170{ }^{\circ} \mathrm{C}$ ) or superior to $20 \%$ (temperatures of $-130^{\circ} \mathrm{C}$ and $-100{ }^{\circ} \mathrm{C}$ ). So, we are outside the validity range defined in conclusion of the round robin initiated by F. Mudry (4)(conclusions of that round robin are subsequent to the beginning of this action). So, we cannot exclude an influence of surface condition of specimens in the case of low level of strain (however, it is unlikely), and of large plasticity in the case of high level of strain.

For temperatures of $-100^{\circ} \mathrm{C}$ and $-130^{\circ} \mathrm{C}$, we see a notable difference between mean levels of strain at fracture obtained by the different laboratories. For temperature of $-170^{\circ} \mathrm{C}$, we detect a difference in terms of mean stresses at fracture between both laboratories. That last 
one may probably be explained by the difference of test control mode between laboratories 2 and 3. The displacement control mode doesn't allow a sollicitation rate very accurate. It probably induces a higher sollicitation rate than extensometer control.

The difference in mean strains at fracture between laboratories for temperatures of $-100{ }^{\circ} \mathrm{C}$ and $-130^{\circ} \mathrm{C}$ may be explained by the different methods used to determine the diameter at fracture (extensometer or post mortem measures). Results obtained by both laboratories show a few singular points. Some fractographic examinations have been done on three specimens, tested at $-130^{\circ} \mathrm{C}$ in order to determine if some metallurgical heterogeneities had induced an intergranular fracture. It appears that we cannot associate systematically intergranular fracture and singular points.

\subsection{First identification of $m$ and $\sigma_{\mathrm{u}}$ parameters}

Table 3 collects parameters of the different procedures used by the three laboratories for the determination of $m$ et $\sigma_{u}$. The rate of mean strain at fracture obtained for temperatures of $-100{ }^{\circ} \mathrm{C}$ and $-130{ }^{\circ} \mathrm{C}$ required an extrapolation of true stress - true strain curves, regarding the plasticity level. Each laboratory uses its own method in the identification procedure.

21 Beremin parameter values have been determined in this first step by the three laboratories. We obtain a large scatter band on the results : $12<\mathrm{m}<65,2200 \mathrm{MPa}<\sigma_{\mathrm{u}}<$ $5097 \mathrm{MPa}$. Main parameters which can influence the determination of $\mathrm{m}$ and $\sigma_{\mathrm{u}}$ are :

- number of experimental results used (taking into account or not singular points),

- method to extrapolate stress - strain curve,

- plasticity correction,

- form of the equation applied to the data (linear or non-linear).

On the other hand, the formulation of the failure probability $P_{f}$ doesn't influence significantly the values of $m$ and $\sigma_{u}$. From that observations, we decided to define the following procedure :

- removal of singular points (arbitrary choice),

- use of a plasticity correction for temperature of $-100^{\circ} \mathrm{C}$ and $-130^{\circ} \mathrm{C}$ (to take

into account high levels of mean strain at fracture),

- use of a linear fit (the non - linear one gives more weight to extreme points),

- use of probability law $n^{\circ} 3$ (it is the easiest one),

Table 4 presents the values of $m$ and $\sigma_{u}$ obtained only with this last procedure (all set of parameters determined with other procedure have been suppressed) : $24<\mathrm{m}<25,2792$ $\mathrm{MPa}<\sigma_{\mathrm{u}}<3094 \mathrm{MPa}$.

\subsection{Second identification of $m$ and $\sigma_{u}$ parameters}

In order to improve the knowledge of the Beremin parameters on this material, a second identification of $\mathrm{m}$ and $\sigma_{\mathrm{u}}$ has been performed using same experimental data. This exercice is conducted by only one laboratory taking into account a single standard identification procedure and all the experimental results at a given temperature (about 40 results at each temperature), excluding singular points.

The experimental results at failure are compared with numerical calculations for each temperature in figure 3 (load versus radial contraction curves). The agreement is very satisfactory at $-130^{\circ} \mathrm{C}$ and $-170^{\circ} \mathrm{C}$ between experimental and numerical results, regarding the scatter on experimental data. At $-100{ }^{\circ} \mathrm{C}$, the agreement is not so good, leading to modify the extrapolation of the stress - strain curve beyond $10 \%$.

Table 5 presents the $m$ and $\sigma_{u}$ values obtained in this new identification. There is no effect of temperature on $\mathrm{m}$ parameter $(24<\mathrm{m}<25)$. In the opposite, $\sigma_{u}$ parameter seems to be more temperature dependent $\left(2650 \mathrm{MPa}<\sigma_{\mathrm{u}}<3100 \mathrm{MPa}\right.$ according the temperature). These values are very similar to previous values exposed in table 4 . 


\subsection{Conclusion}

The identification of Beremin model parameters $\mathrm{m}, \sigma_{u}$ has been conducted by three laboratories on an $\mathrm{A} 508 \mathrm{Cl3}$ steel at three temperatures $\left(-170{ }^{\circ} \mathrm{C},-130^{\circ} \mathrm{C}\right.$ and $\left.-100{ }^{\circ} \mathrm{C}\right)$ using classical axisymmetrical notched tensile specimens. Parameters deduced from a first identification exhibit a very large scatter probably due to an identification procedure different from a laboratory to another. The definition of such a procedure appears absolutely necessary, regarding the scatter of results obtained.

A complementary identification has been conducted using a single identification procedure. A new set of $\mathrm{m}$ and $\sigma_{\mathrm{u}}$ parameters has been defined for each temperature. There is no effect of temperature on $\mathrm{m}(24<\mathrm{m}<25)$. In the opposite, $\sigma_{\mathrm{u}}$ parameter seems more temperature dependent (2650 MPa $<\sigma_{u}<3100 \mathrm{MPa}$ according the temperature).

\section{4 - THE USE OF BEREMIN MODEL IN FINITE ELEMENT COMPUTATIONS}

\subsection{Sensitivity of Beremin model to numerical aspects and recommandations for computations}

As mentioned earlier, the application of local approach to fracture with fracture damage not coupled with plasticity requires the computation of elastic - plastic stress - strain fields. For cracked specimens, due to steep stress - strain gradients, a very refined mesh is required (5)(6). Moreover, the results could depend on the mesh size and therefore vary from one user to another, which would certainly be undesirable. The results are also sensitive to the $\sigma_{\mathrm{w}}$ Weibull stress computation method, i.e. considering average stress in the elements or stress at the Gauss points $(5)(6)$.

In order to explore these points, a two - dimensional numerical analysis of a CT50 specimen (net thickness : $50 \mathrm{~mm}$, a/W : 0.55) was undertaken (6). These computations are performed using plane - strain assumption and Sysweld finite element programme. Four meshes are used with different square element sizes at the crack tip : $25 \mu \mathrm{m}, 50 \mu \mathrm{m}, 200 \mu \mathrm{m}$ and 400 $\mu \mathrm{m}$. The computations are performed using the mechanical properties of base metal A508 $\mathrm{Cl} 3$ steel determined at $-170^{\circ} \mathrm{C}$. The $\sigma_{w}$ Weibull stress is calculated using two methods : "partial gauss method" (taking into account the principal stress at the Gauss points) and "partial method" (average principal stress in the element). The parameters of the model used in the present study are those usually used by Framatome in the safety analyses : $m=22$ and $\sigma_{\mathrm{u}}=2630 \mathrm{MPa}$.

The stress intensity factor (S.I.F.) $\mathbf{K}_{\mathrm{J}}$ is deduced from the elastic - plastic computation of the $\mathrm{J}$ integral. It is evident that the stress intensity factor $\mathrm{K}_{\mathrm{J}}$ does not depend on the mesh used. The Weibull stress $\sigma_{w}$ is calculated for each mesh with both options previously described. The results are presented in figure 4 (Weibull stress, $\sigma_{w}$, versus S.I.F., $K_{\mathrm{J}}$, curves). The results show that the Weibull stress, $\sigma_{w}$, is dependent on whether one takes into account the stress at the Gauss points ("partial gauss" option) or one averages stress in each element ("partial" option). Higher Weibull stress values are obtained in the first case because the averaging procedure decreases the peak stress recorded in each element. The results also show that the Weibull stress $\sigma_{w}$ can be very dependent on the mesh size unless it is sufficiently refined. Considering those results, we show that the use of $50 \mu \mathrm{m}$ square elements at the crack tip is sufficient since results are similar with $25 \mu \mathrm{m}$ or $50 \mu \mathrm{m}$ square elements. In contrast, the use of larger elements $(200 \mu \mathrm{m}$ or $400 \mu \mathrm{m})$ at the crack tip is not sufficient. In this case, the Weibull stress, $\sigma_{w}$, (and, consequently, the probability of cleavage fracture) is strongly underestimated.

We therefore recommend the use of a mesh size of $50 * 50 \mu \mathrm{m}$ square elements and the "partial" option in the use of local approach to cleavage fracture (Beremin model) and the computation of Weibull stress.

\subsection{Comparison of finite element programmes on some applications}

In order to compare and validate finite element programmes in the field of local approach to cleavage fracture, several two - dimensional numerical benchmark have been performed between EDF, CEA, Framatome and AEA Technology with respective F.E. programmes Aster, Castem 2000, Systus and Abaqus. Due to strong sensitivity of Beremin model to 
numerical aspects, as previously described, specifications have been imposed before the computations regarding the mesh (use of square eight noded elements of $50 \mu \mathrm{m}$ by $50 \mu \mathrm{m}$ at the crack tip), the F.E. analysis (small strain, elastic-plastic calculation) and the $\sigma_{w}$ Weibull stress computation method (considering average stresses in the elements instead of stresses at Gauss points).

Two examples are briefly discussed in this paper, the analysis of a conventional CT25 specimen $(\mathrm{a} / \mathrm{W}=0.55)$ under mechanical loading, and the calculation of a cladded vessel with small subclad flaw under thermal loading (flaw depth $6,2 \mathrm{~mm}$ with $0,2 \mathrm{~mm}$ tip in cladding in order to evaluate the stress intensity factor at the crack tip in cladding, a/W $\approx$ 0.03 ). In each case, the benchmark includes the comparison of numerous parameters of the elastic - plastic analysis in addition of $\sigma_{w}$ Weibull stress evaluation (crack opening, opening stress at the crack tip, stress intensity factor $\mathrm{K}_{\mathrm{J}} \ldots$...).

Main results of these calculations are presented in detail in paper (7). The agreement on conventional parameters (COD, opening stress, stress intensity factor ...) is generally very satisfactory. The evolution of the $\sigma_{w}$ Weibull stress during the loading is shown on figure 5 for the CT specimen and the cladded vessel. The agreement between different computations is quite good in case of increasing loading (CT specimen, first part of the thermal transient for the vessel). This agreement is always quite good during the decreasing part (decreasing of the stress intensity factor $K_{\mathrm{j}}$ ) of the thermal transient between three computations but some differences appear with the fourth computation. It is due to the fact that, in the corresponding F.E. programme, the elements under unloading are not taken into account in the calculation of the Weibull stress $\sigma_{w}$ (the stress is in this case fixed to zero).

Other comparisons have been performed in the frame of this action, confirming the good agreement between Aster, Castem 2000, Systus and Abaqus F.E. programmes in the field of local approach to cleavage fracture (Beremin model).

However, we must remind the strong sensitivity of the Beremin model to numerical aspects. It is necessary, when using this type of approach, to always keep same specifications (e.g. mesh size at the crack tip).

\section{5 - APPLICATION OF BEREMIN MODEL IN REACTOR PRESSURE VESSELS}

\subsection{Thermal transient on cladded vessels containing small subclad flaw}

Among different analyses conducted, the behavior of two cladded vessels submitted to a thermal transient has been studied using local approach to cleavage fracture. Results are presented in detail in paper (7) and are summarized in this section.

Two cladded vessels with small subclad flaw are considered, differing only by the flaw depth. The base metal of the vessel is a classical A508 C13 steel and the cladding is a A309L - A308 L austenitic stainless steel. The main dimensions are the following :

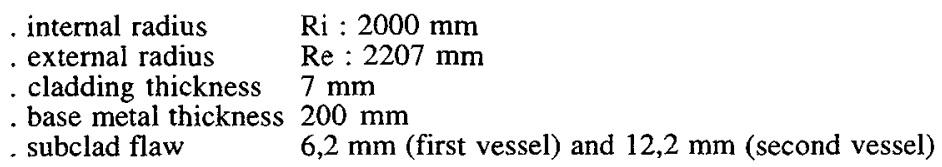

The flaw taken into account in both cases is an axisymmetrical subclad flaw, including a 0,2 $\mathrm{mm}$ tip in cladding in order to calculate the stress intensity factor $\mathrm{K}_{\mathrm{J}}$ at the crack tip in cladding. The materials properties taken into account in this work are described in detail (7). Each vessel is submitted to a thermal transient applied on the inner cladded surface, without pressure (7). As the use of Beremin model requires a great care in the mesh refinement, the refined zone at the crack tip in base metal is similar for both cladded vessels, constituted by $50 \mu \mathrm{m}$ by $50 \mu \mathrm{m}$ eight noded square elements.

The respective analyses are conducted using two - dimensional elastic - plastic computations. The calculation of a CT specimen $(\mathrm{a} / \mathrm{W}=0.55)$ is conducted in parallel, using 
same mechanical properties as base metal of vessels and same mesh refinement at the crack tip ( $50 \mu \mathrm{m}$ by $50 \mu \mathrm{m}$ eight noded square elements).

\subsection{A shallow flaw effect suggested by comparison between CT specimen and cladded vessels}

As paper (7) gathers almost results, we focus only on the application of the Beremin model on both vessels and CT specimen. The comparison between these specimens is made using Weibull stress $\sigma_{w}$ versus Stress intensity factor $K_{\mathrm{j}}$ curves (figure 6 ).

We can notice significant differences between three specimens. The Weibull stress $\sigma_{w}$ in the CT specimen and in the cladded vessels, very similar for low values of the applied stress intensity factor $\mathrm{K}_{\mathrm{j}}$, are very different for higher values of $\mathrm{K}_{\mathrm{J}}$. It means that the probability of failure evaluated with this model (Beremin model) can be very different between the CT specimen, the vessel with a $12,2 \mathrm{~mm}$ deep flaw and the vessel with a $6,2 \mathrm{~mm}$ deep flaw, although the applied stress intensity factors $K_{J}$ in the different structures are identical. For a given level of the applied stress intensity factor $K_{\mathrm{J}}$, the higher probability of failure (the higher Weibull stress $\sigma_{w}$ ) is obtained on the specimen containing the deeper crack (CT specimen with $\mathrm{a} / \mathrm{W}=0.55$ ). We notice the same effect between the two vessels, with a higher probability of failure on vessel with a $12,2 \mathrm{~mm}$ deep flaw $(\mathrm{a} / \mathrm{W} \approx 0.03$ in one case, $\mathrm{a} / \mathrm{W} \approx$ 0.06 in the other case).

Furthermore, other significant differences are noticed between specimens : decreasing opening stress on the cracked ligaments and increasing of the plastic zone size for the specimens with short crack (7).

These results suggest a shallow flaw effect (increasing of cleavage fracture toughness on specimens with short cracks) due to very different values of a/W ratio between respective specimens $(6)(7)(8)$. The application of Beremin model shows higher cleavage failure probability for specimens containing deeper cracks.

\section{6 - THE CONSTRAINT EFFECT IN CLEAVAGE FRACTURE}

Conventional fracture mechanics assumes that the levels of stress and strain local to the crack tip are characterised by a single parameter. The extent of these single - parameter fields is determined by the geometry, size, and mode of loading of the cracked structure. It is now recognised that fracture toughness is a material property characterised by a single parameter $\left(\mathrm{K}_{\mathrm{I}}\right.$ or $\left.\mathrm{J}\right)$ only in special circumstances which involve a high degree of constraint at the crack - tip. Thus, the apparent toughness of a material is influenced by the size and shape of the crack, the geometry of the structure and the mode of loading imposed. Recent studies have attempted to describe fracture more fully in terms of $K_{1}$ or $J$ and a second parameter. The second parameter provides information concerning how the structural and loading configuration influences crack - tip constraint which $\mathrm{J}$ on its own is unable to convey. One particular candidate parameter is the elastic $T$ stress (the first non - singular term in the Williams crack tip field expansion) which is directly proportional to the load applied to the cracked geometry (9).

This section presents the results of analytical studies in which the Beremin model (1)(2)(3) is used to predict the influence of constraint on cleavage fracture behaviour. The model is first used to demonstrate its ability to predict shifts in fracture toughness as a function of constraint. Secondly, the model is used to predict toughness as a function of crack depth for a mild steel plate tested in four - point bending. The results are then compared with experimental data $(8)(10)$.

\subsection{The shallow flaw effect shown by numerical calculations}

The modified boundary layer (MBL) analysis is a convenient approach to assessing the influence of $\mathrm{K}$ and $\mathrm{T}$ on crack - tip behaviour. The analysis represents a crack in an infinite body which is subjected to a $K_{1}$ and $T$ field (figure 7 ) imposed by displacing nodes situated on the outer boundary of the model. These displacements are a function of $K_{1}, T, r$ and $\theta$ (polar co-ordinates of each boundary node originating at the crack tip)(11). The model used eight noded reduced integration elements. The crack-tip region was modelled by an 
array of square $50 \mu \mathrm{m}$ by $50 \mu \mathrm{m}$ elements, and the ratio of minimum element size to model radius was $3 \cdot 10^{5}$.

Three analyses were performed with $\mathrm{K}_{\mathrm{I}}<200 \mathrm{MPa} \cdot \sqrt{\mathrm{m}}$ and $\mathrm{T} / \sigma_{\mathrm{y}}=0.0$ (high constraint), - 0.5 (medium constraint) and - 1.0 (low constraint). The material stress - strain behaviour followed a Ramberg-Osgood hardening law with exponent $n=15$. The parameters used in the Beremin model were typical of pressure vessel steels with $\mathrm{m}=18, \sigma_{u}=2750 \mathrm{MPa}$ and $\mathrm{V}_{0}=(50 \mu \mathrm{m})^{3}$. The results, illustrated in figure 8 , indicate an increase in predicted cleavage toughness with decreasing constraint for a given failure probability. For the Beremin parameters used, a reduction in constraint from $\mathrm{T} / \sigma_{\mathrm{y}}=0.0$ to -1.0 increases the predicted mean toughness by approximately $15 \%$.

Numerical calculations have been performed at the same time on different cracked specimens to confirm the shallow flaw effect in cleavage fracture (12). Several geometrical configurations are taken into account :

. CT specimen with a/W $=0.55$

. Four point-bending cracked specimens with the following values of a/W : $0.55,0.2$ and $0.05(\mathrm{~W}=100 \mathrm{~mm}$ in each case)

Four point-bending specimen (cladding thickness $7 \mathrm{~mm}$ ) with a subclad flaw (a/W $=0.05$, total thickness $107 \mathrm{~mm}$ )

Cladded specimens containing an underclad crack (DSR4, DSR1, DSR3 and DD2 with $0.033<\mathrm{a} / \mathrm{W}<0.108$ ).

The mesh refinement at the crack tip is identical for each specimen (square elements of 50 $\mu \mathrm{m}$ by $50 \mu \mathrm{m})$. The elastic - plastic computation of each specimen is conducted with the Sysweld finite element program (plane strain assumption, small scale yielding condition). The stress - strain curve used in the computations is the curve determined at $-170^{\circ} \mathrm{C}$ on the A508 C13 ferritic steel of cladded specimens tested in the frame of a large experimental programme (6)(yield strength : $768 \mathrm{MPa}$, Young modulus : $210000 \mathrm{MPa}$ ). The Weibull parameter $m$ taken into account for the calculation of the Weibull stress $\sigma_{\mathrm{w}}$ is $\mathrm{m}=22$.

The comparison between different specimens is made on figure 9 using Weibull stress $\sigma_{w}$ versus stress intensity factor $K_{\mathrm{J}}$ curves. The effect of $a / W$ ratio on $\sigma_{w}$ versus $K_{\mathrm{J}}$ curves is clear. The Weibull stress $\sigma_{w}$, similar for very low values of the stress intensity factor, differs markedly in different specimens as soon as the loading (and plasticity in base metal) increases. The evolution is perfectly correlated with a/W ratio : for a given level of the stress intensity factor, higher values of Weibull stress (consequently higher values of the probability of cleavage fracture) are obtained in specimens containing deeper cracks. These observations confirm the shallow flaw effect previously suggested. That means that, for a same probability of failure, higher cleavage fracture toughness is obtained on specimens containing short cracks (loss of constraint).

The comparison between different cracked specimens is completed by examinating the evolution of stress fields and plastic zones at the crack tip during the loading (12). Significant differences are observed between each specimen. For a same level of loading $\left(K_{y}\right)$, we notice a decrease of stresses $\sigma_{x}$ (parallel to crack) and $\sigma_{y}$ (opening stress) on the ligament at the crack tip and a marked increase of the plastic zone size in specimens with shallow crack.

This parametric study confirms thus the results on constraint effect presented in the first part of this section.

\subsection{Experimental application}

The Beremin model model was used to predict the fracture response of a $25 \mathrm{~mm}$ thick mild steel plate tested by Sumpter (8)(10). Model parameters $\mathrm{m}$ and $\sigma_{\mathrm{u}}$ were derived, from analyses undertaken with respect to the deeply crack bend specimens, as 19 and $1650 \mathrm{MPa}$ respectively $\left(\mathrm{V}_{0}=(50 \mu \mathrm{m})^{3}\right)(8)$.

Predicions of cleavage toughness, $J_{c}$ as a function of $a / W$, figure 10 , show a significant influence of crack depth on cleavage toughness. When compared to experimental data, figure 11, the Beremin model predicts an upswing in cleavage fracture toughness as a function of decreasing crack-tip constraint which is conservative with respect to the actual materials response. 


\subsection{Synthesis}

The results presented in figures $8,9,10,11$ have demonstrated that the Beremin cleavage fracture model is able to predict an influence of crack - tip constraint on fracture toughness. First, the approach predicts a significant increase in cleavage fracture toughness as a function of decrease in crack-tip constraint, the degree of elevation in cleavage toughness being sensitive to the constraint of the structure and the value of $P_{f}$ considered. Secondly, the predicted elevation in toughness as a function of decreasing crack - tip constraint follows the same trend as that observed in the experimental data. However, for bend specimens with $a / W<0.15$ and $T / \sigma_{y}<-0.6$, the predicted increase in $J_{c}$ is less marked than that observed experimentally. The local approach predictions of cleavage fracture are therefore conservative with respect to the experimental data for low constraint geometries. Finally, the local approach predicts an increase in the amount of scatter in toughness as a function of decreasing crack-tip constraint. This increase in scatter is most clearly seen with reference to the Weibull distributions illustrated in figure 10. For SECB specimens with $a W$ $=0.5$ the scatter in fracture toughness data $\left(J_{c}^{p=0.95}-J_{c}^{p=0.05}\right)$ is predicted to be $42 \mathrm{~kJ} / \mathrm{m}^{2}$. By comparison, the predicted scatter for specimens with a $\mathrm{W}=0.025$ is $139 \mathrm{~kJ} / \mathrm{m}^{2}$. This is an inevitable consequence of framing the local approach model within two - parameter Weibull statistics since the lower bound value of $J_{c}$ is pinned to zero and the mean increases with decreasing constraint.

\section{7 - CONCLUSION}

A cooperative research programme in the field of local approach to cleavage fracture applied to reactor pressure vessels is conducted between EDF, CEA, Framatome and AEA Technology including an experimental part on notched tensile specimens and numerical computations.

The identification of Beremin model parameters $\mathrm{m}, \sigma_{\mathrm{u}}$ has been conducted by three laboratories on an $\mathrm{A} 508 \mathrm{Cl} 3$ steel at three temperatures $\left(-170^{\circ} \mathrm{C},-130^{\circ} \mathrm{C}\right.$ and $-100{ }^{\circ} \mathrm{C}$ ) using classical axisymmetrical notched tensile specimens. Parameters deduced from a first identification exhibit a very large scatter probably due to an identification procedure different from a laboratory to another. A complementary identification has been conducted in a second step using a standard identification procedure. A new set of $\mathrm{m}$ and $\sigma_{\mathrm{u}}$ parameters has been defined for each temperature. There is no effect of temperature on $\mathrm{m}$ parameter $(24<\mathrm{m}<25)$. In the opposite, $\sigma_{u}$ parameter seems to be more temperature dependent (2650 $\mathrm{MPa}<\sigma_{\mathrm{u}}<3100 \mathrm{MPa}$ according the temperature).

Several two - dimensional numerical computations have been performed by partners with respective finite element programmes Aster, Castem 2000, Systus and Abaqus in order to compare and validate programmes in the field of local approach to cleavage fracture. The comparisons on some reference calculations (mechanical and thermal loading) show generally a very good agreement in case of increasing loading. This agreement is always quite good for decreasing loading between three codes but some differences are noticed with the fourth code, due to the fact that the elements under unloading are not taken into account in the calculation of Weibull stress $\sigma_{w}$. The strong sensitivity of Beremin model to numerical aspects has been showed, leading to impose some specifications before the computations regarding the mesh, the finite element analysis and the $\sigma_{w}$ Weibull stress computation method.

The ability of the Beremin model to predict an influence of crack - tip constraint on fracture toughness has been finally demonstrated. This model predicts a significant increase in cleavage fracture toughness as a function of decrease in crack - tip constraint. This prediction follows the same trend as that observed on experimental data.

\section{ACKNOWLEDGEMENTS}

Main part of this work has been carried out in the framework of a cooperative action between EDF, CEA, Framatome and AEA Technology. Helpful discussions with partners were appreciated. The authors would also like to thank Mr Faidy, Mr Rousselier and $\mathrm{Mr}$ Pellissier - Tanon who have initiated this action. 


\section{REFERENCES}

(1) F. Mudry

"Etude de la rupture ductile et de la rupture par clivage d'aciers faiblement alliés ". Thèse d'Etat, Université de Technologie de Compiègne, 1982.

(2) BEREMIN, F.M.

"A local criterion for cleavage fracture of a nuclear pressure vessel steel ". Metallurgical Transactions A, vol. 14A, p. 2277-2287, 1983.

(3) F. Mudry

"A local approach to cleavage fracture". International Seminar on Local Approach of Fracture, Moret-sur-Loing, 1986.

\section{(4) F. Mudry, M. Di Fant}

"A round robin on the measurement of local criteria ". IRSID report $\mathrm{n}^{\circ}$ RE 93.319, 1993.

(5) J. Brochard, A. Combescure, S. Ignaccolo, G. Mottet

"On the numerical variabilities in applying the local criterion for cleavage fracture ". SMIRT Conference, Stuttgart, 1993.

(6) D. Moinereau, G. Rousselier

"The analysis of underclad cracks in large-scale tests using the local approach to cleavage fracture ". 27th ASTM National Symposium on Fatigue and Fracture Mechanics, Williamsburg, 1995.

(7) D. Moinereau, J. Brochard, D. Guichard, S. Bhandari, A. Sherry, C. France

"Local approach of cleavage fracture applied to a vessel with subclad flaw. A benchmark on computational simulation ". ASME-PVP Conference, Montreal, 1996.

(8) A.H. Sherry, D.J. Sanderson, D.P.G. Lidbury, R.A. Ainsworth, K. Kikuchi

"The application of local approach to assess the influence of in-plane constraint on cleavage fracture ". PVP-Vol. 304, Fatigue and Fracture Mechanics in Pressure Vessels and Piping, Joint ASME/JSME Pressure Vessel and Piping Conference, Hawaï, 1995.

\section{(9) A.H. Sherry, C.C. France, M.R. Goldthorpe}

"Compendium of T-stress solutions for two and three dimensional geometries ", Fatigue Fract. Engng. Mater. Struct. Volume 18m 141-155, 1995.

\section{(10) J.D.G. Sumpter}

"An experimental investigation of the T-stress approach ". Constraint Effects in Fracture, ASTM STP 1171, E.M. Hackett, K.H. Schwalbe and R.H. Dodds, Eds., ASTM, pp. 492-502, 1993.

(11) B.A. Bilby, G.E. Cardew, M.R. Goldthorpe, I.C. Horward

"Fourth report on the stability of cracks in tough materials : an investigation of the effect of specimen geometry on the fields of stress and strain at the tips of stationary cracks ". Department of Mechanical Engineering, University of Sheffield, 1986.

(12) D. Moinereau

"The shallow flaw effect and the local approach to cleavage fracture ". ASME-PVP Conference, Montreal, 1996.

Table 1: Chemical composition of the studied material (weight \%)

\begin{tabular}{|c|c|c|c|c|c|c|c|c|c|c|c|}
\hline $\mathrm{C}$ & $\mathrm{S}$ & $\mathrm{P}$ & $\mathrm{Mn}$ & $\mathrm{Si}$ & $\mathrm{Ni}$ & $\mathrm{Cr}$ & $\mathrm{Mo}$ & $\mathrm{V}$ & $\mathrm{Cu}$ & $\mathrm{Co}$ & $\mathrm{Al}$ \\
\hline 0.18 & 0.004 & 0.006 & 1.32 & 0.19 & 0.73 & 0.17 & 0.51 & $<0.01$ & 0.07 & $\leq 0.01$ & 0.016 \\
\hline
\end{tabular}


Table 2: Number of specimens tested at each temperature

\begin{tabular}{|c|c|c|c|}
\hline $\begin{array}{c}\text { Temperature } \\
\left({ }^{\circ} \mathrm{C}\right)\end{array}$ & Laboratory 1 & Laboratory 2 & Laboratory 3 \\
\hline-170 & - & 20 & 20 \\
\hline-130 & 20 & - & 20 \\
\hline-100 & 20 & 20 & - \\
\hline
\end{tabular}

Table 3 : Parameters of the different numerical procedures used by the three laboratories for the determination of Beremin model parameters

\begin{tabular}{|c|c|c|c|}
\hline & Laboratory 1 & Laboratory 2 & Laboratory 3 \\
\hline Code & Abaqus & Castem 2000 & Sysweld \\
\hline Mesh generating software & Ideas & Gibi & Sysweld \\
\hline Element & CAX8R & QUA 8 & QUA 8 \\
\hline $\begin{array}{l}\text { Mesh size at the level of } \\
\text { the smallest section }(\mu \mathrm{m})\end{array}$ & 500 & 500 & 500 \\
\hline $\begin{array}{l}\text { Extrapolation of true stress } \\
\text { - true strain curves } \\
\text { (test temperatures }:-130 \\
{ }^{\circ} \mathrm{C} \text { and }-100^{\circ} \mathrm{C} \text { ) }\end{array}$ & $\begin{array}{l}\text { Extrapolation of the } \\
\text { experimental curve } \\
\text { by a power law and } \\
\text { adjustement from } \\
\text { load / } \Delta \Phi \text { curve }\end{array}$ & $\begin{array}{c}\text { Extrapolation of the } \\
\text { experimental curve } \\
\text { by a power law } \\
\text { or } \\
\text { extrapolation of the } \\
\text { experimental curve } \\
\text { by a power law and } \\
\text { adjustement from } \\
\text { load / } \Delta \Phi \text { curve }\end{array}$ & $\begin{array}{l}\text { Extrapolation of the } \\
\text { experimental curve } \\
\text { by a power law fitted } \\
\text { on last } 3 \\
\text { experimental points }\end{array}$ \\
\hline $\begin{array}{l}\text { Use of a plasticity } \\
\text { correction for high levels } \\
\text { of mean strain }\end{array}$ & Yes & Yes/No & No \\
\hline Probability law $(*)$ & 1,2 and 3 & $\overline{3}$ & 3 \\
\hline Fit $\left(^{(*)}\right)$ & $\begin{array}{l}\text { Linear and non- } \\
\text { linear }\end{array}$ & Linear & Linear \\
\hline
\end{tabular}

$\left.{ }^{*}\right):$ Law $n^{\circ} 1: \mathrm{PR}_{\mathrm{R}}=\frac{\mathrm{i}-0,3}{\mathrm{~N}+0,4} /$ Law $\mathrm{n}^{\circ} 2: \mathrm{PR}_{\mathrm{R}}=\frac{\mathrm{i}-0,5}{\mathrm{~N}} /$ Law $\mathrm{n}^{\circ} 3: \mathrm{PR}_{\mathrm{R}}=$ $\frac{\mathrm{i}}{\mathrm{N}+1} \quad(\mathrm{i}=1$ to $\mathrm{N})$

$\left.{ }^{* *}\right)$ : Non-linear : $m$ and $\sigma_{\mathfrak{u}}$ are determined directly from the relation $P_{f}-\sigma_{W}$,

Linear : $m$ and $\sigma_{u}$ are determined from the relation $\ln \left(-\ln \left(1-P_{f}\right)\right)=m \ln \sigma W / \sigma_{u}$

Table 4 : Set of Beremin parameters for pressure vessel steel at temperatures of - $100{ }^{\circ} \mathrm{C}$, $130^{\circ} \mathrm{C}$ and $-170^{\circ} \mathrm{C}$.

\begin{tabular}{|c|c|c|}
\hline $\begin{array}{c}\text { Temperature } \\
\left({ }^{\circ} \mathrm{C}\right)\end{array}$ & $\mathrm{m}$ & $\begin{array}{c}\sigma_{\mathrm{u}} \\
(\mathrm{MPa})\end{array}$ \\
\hline-170 & 24 & 2792 \\
\hline-130 & 25 & 3094 \\
\hline-100 & 25 & 2921 \\
\hline
\end{tabular}


Table 5 : Set of Beremin parameters for pressure vessel steel at temperatures of $-100{ }^{\circ} \mathrm{C},-$ $130^{\circ} \mathrm{C}$ and $-170^{\circ} \mathrm{C}$. (final identıfication)

\begin{tabular}{|c|c|c|}
\hline $\begin{array}{c}\text { Temperature } \\
\left({ }^{\circ} \mathrm{C}\right)\end{array}$ & $\mathrm{m}$ & $\begin{array}{c}\sigma_{\mathrm{u}} \\
(\mathrm{MPa})\end{array}$ \\
\hline-170 & 24 & 2650 \\
\hline-130 & 25 & 3100 \\
\hline-100 & 24 & 2960 \\
\hline
\end{tabular}

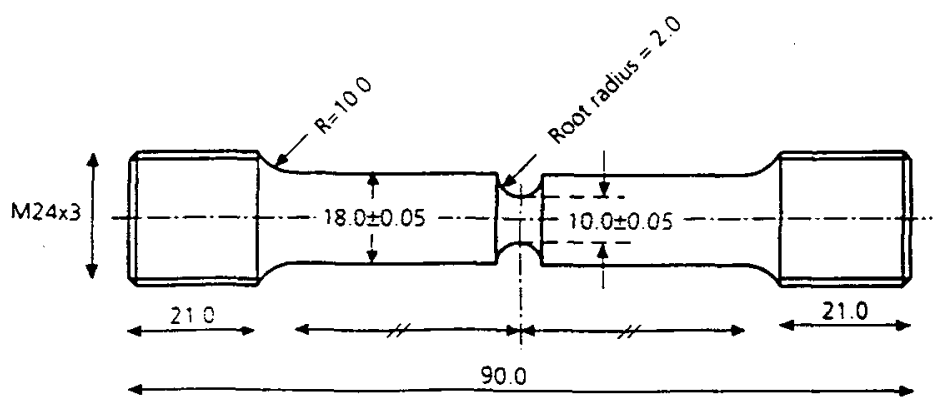

Figure 1: Geometry of notched tensile specimen (in $\mathrm{mm}$ )

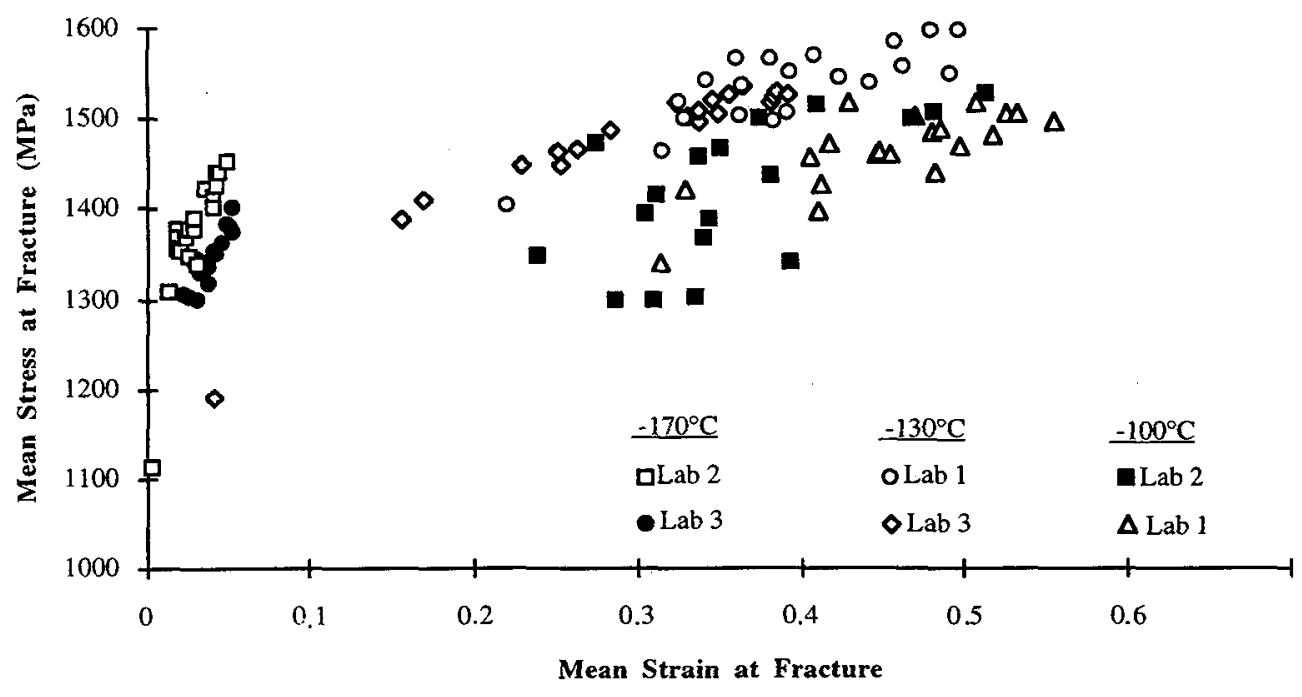

Figure 2: Experimental mean stress at fracture vs. mean strain at fracture obtained from notched tensile tests performed at $-100^{\circ} \mathrm{C},-130^{\circ} \mathrm{C}$ and $-170^{\circ} \mathrm{C}$ 

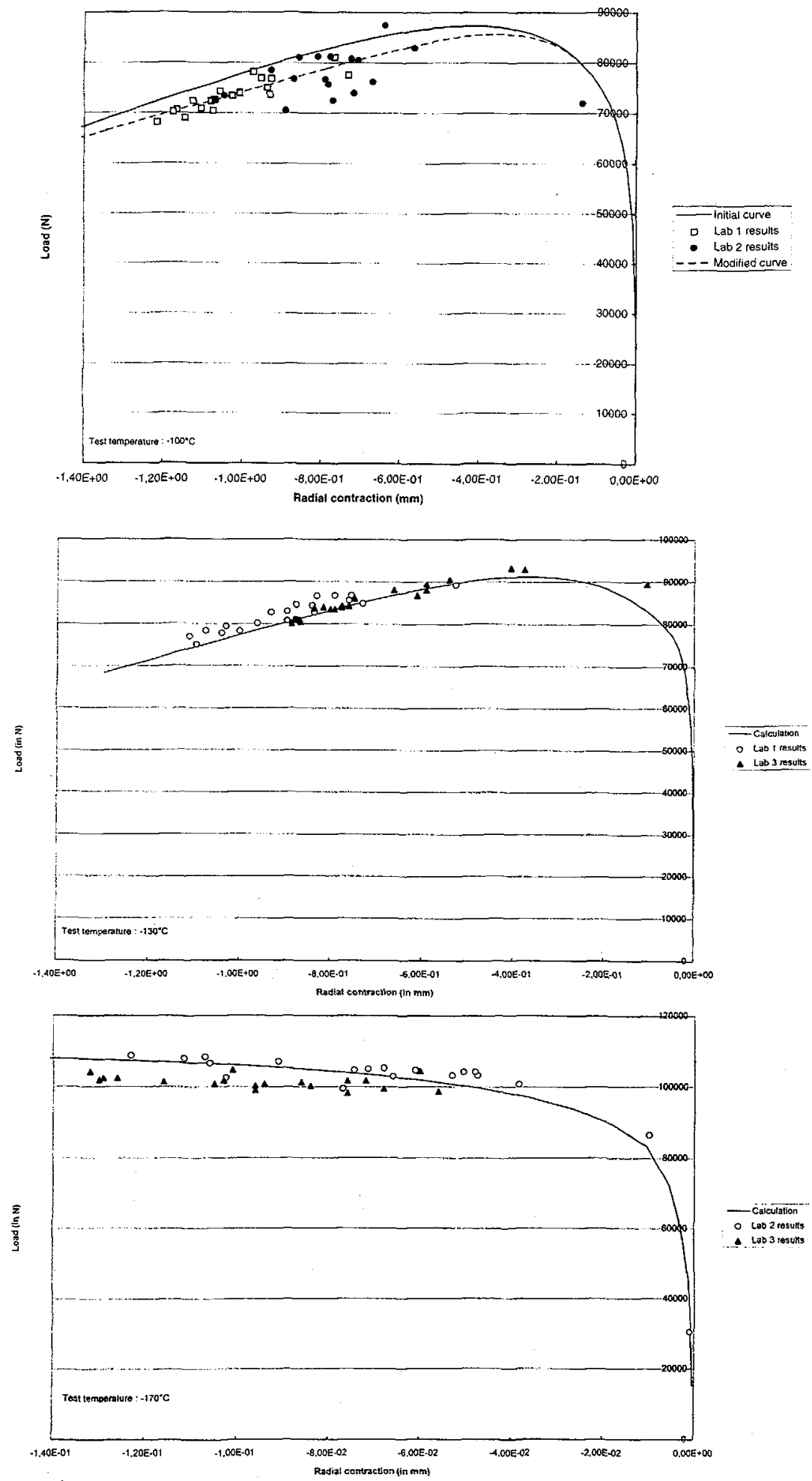

Figure 3 : Load versus radial contraction curves of notched tensile specimens. Comparison between experimental results at failure and numerical calculations 
WEIBULL STAESS (MPa)

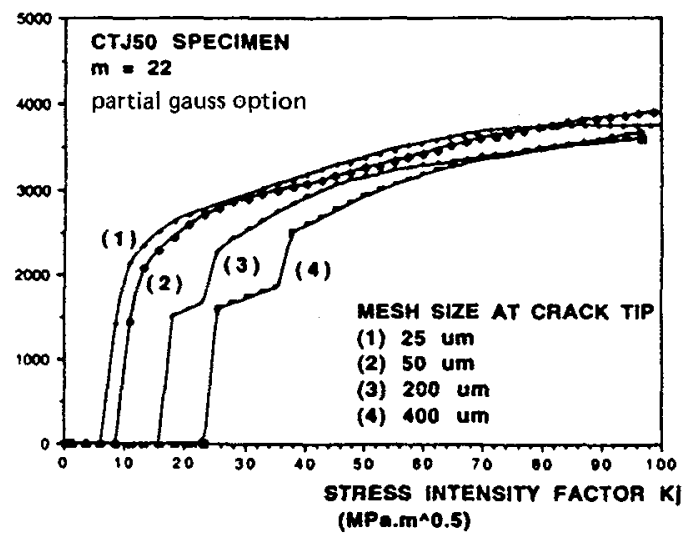

WEIBULL STAESB (MPA)

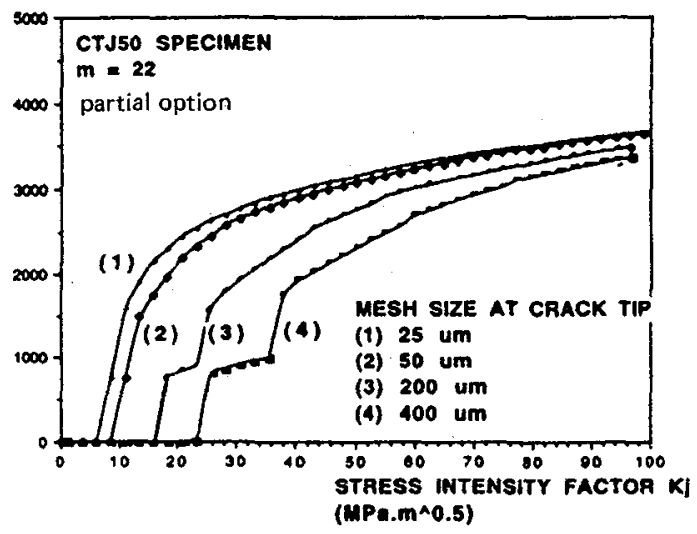

Figure 4 : Weibull stress versus stress intensity factor $K_{1}$ curve for the CT specimen

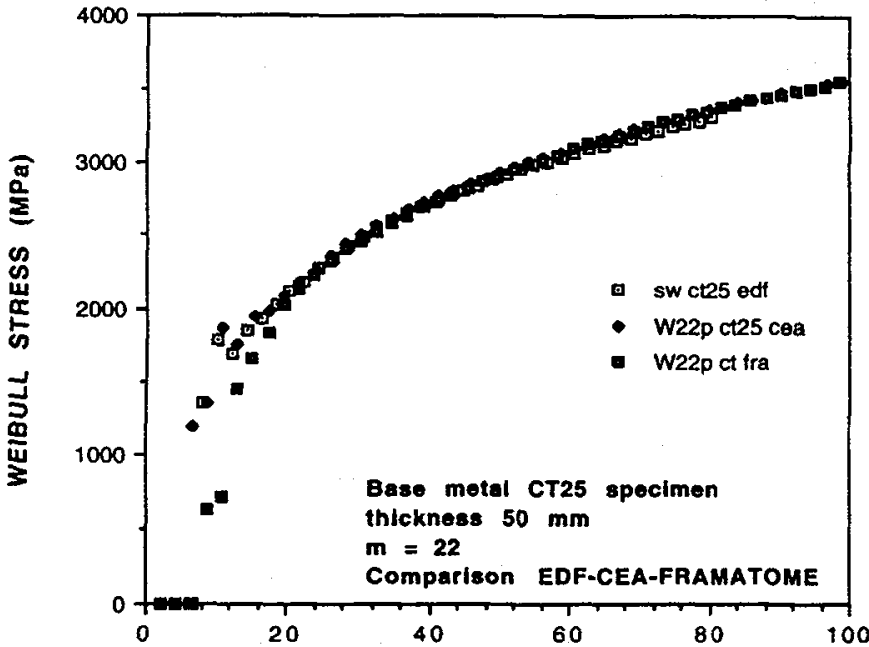

STRESS INTENSITY FACTOR K| (MPa.m^0.5)

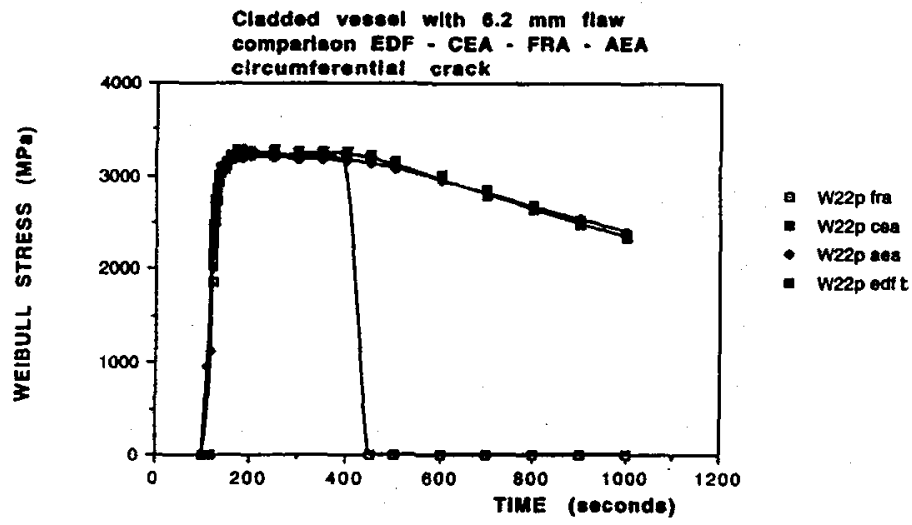

Figure 5 : Calculation of $\sigma_{w}$ Weibull stress on a CT specimen and a cladded vessel with subclad flaw. Comparison between F.E. programmes 


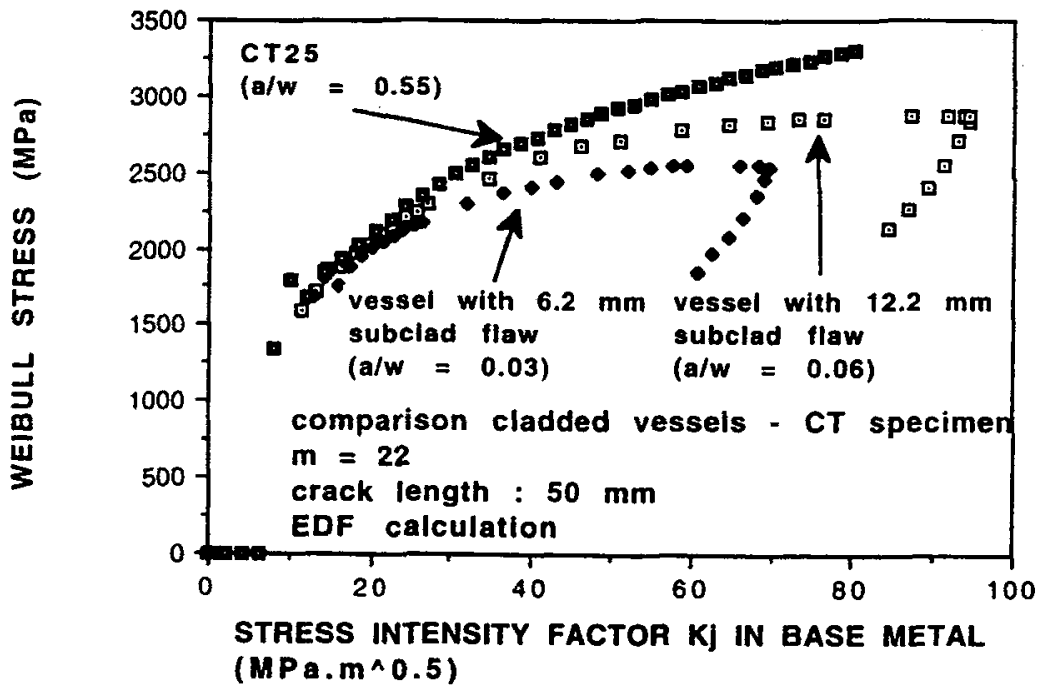

Figure 6 : Comparison between cladded vessels and CT specimen using Beremin model $\left(\sigma_{w}\right.$ versus $\mathrm{K}_{\mathrm{J}}$ curve)

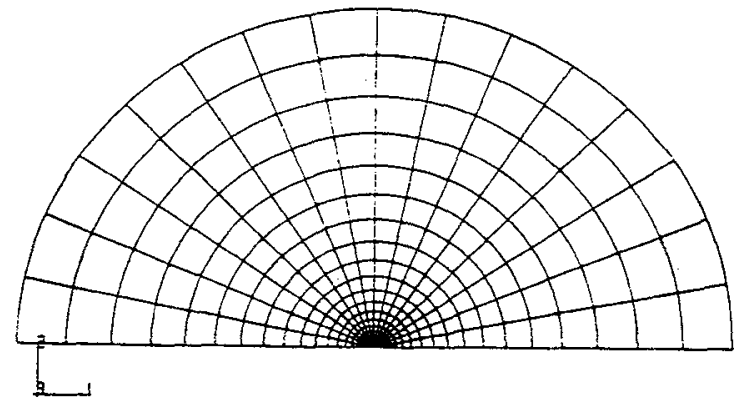

Figure 7 : Modified boundary layer model

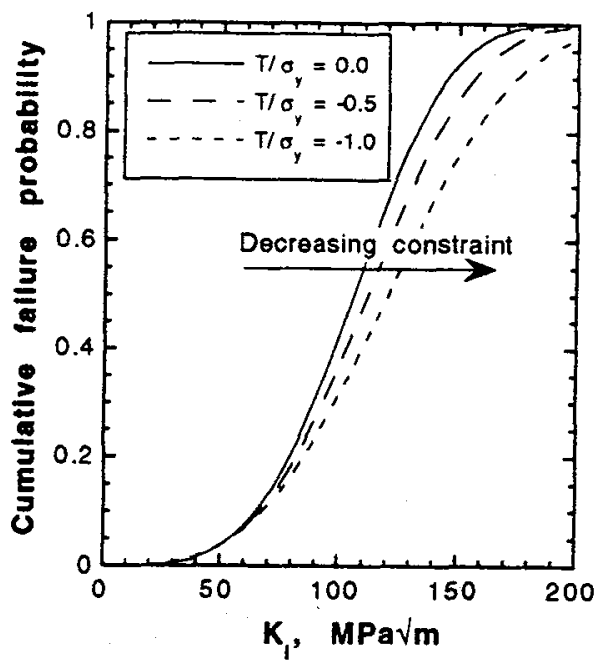

Figure 8 : Influence of constraint on the variation of cumulative failure probability with stress intensity factor 


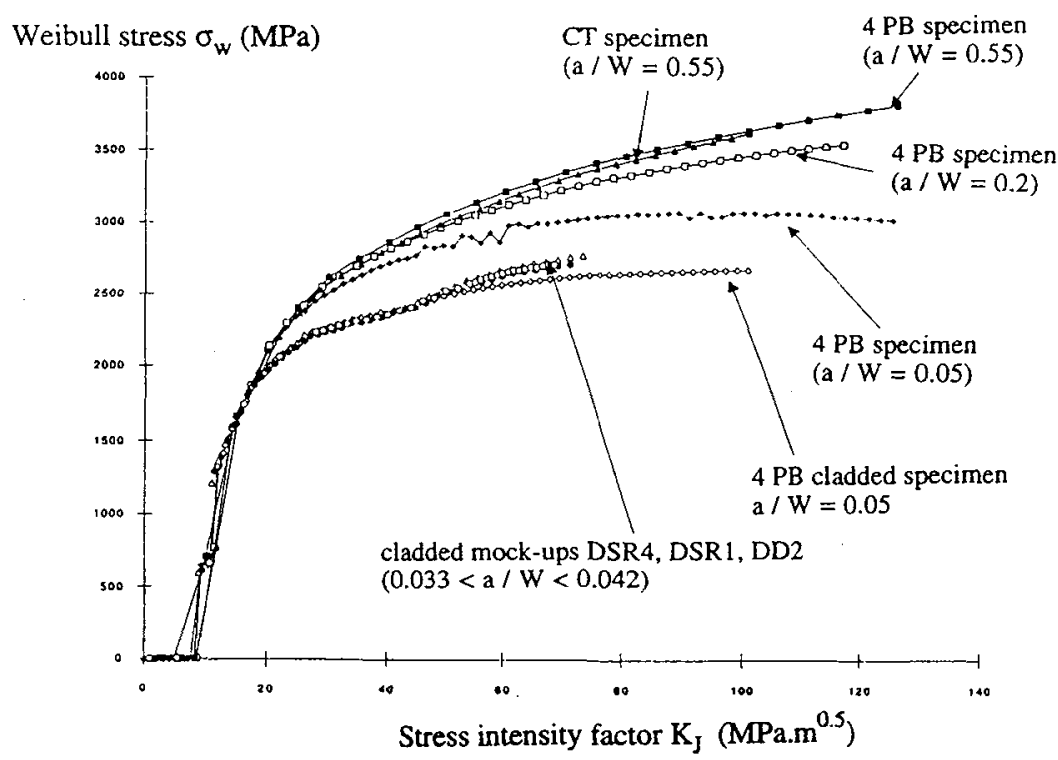

Figure 9 : Weibull stress $\sigma_{\mathrm{w}}$ versus stress intensity factor $\mathrm{K}_{\mathrm{J}}$ curve. Comparison between different cracked specimens

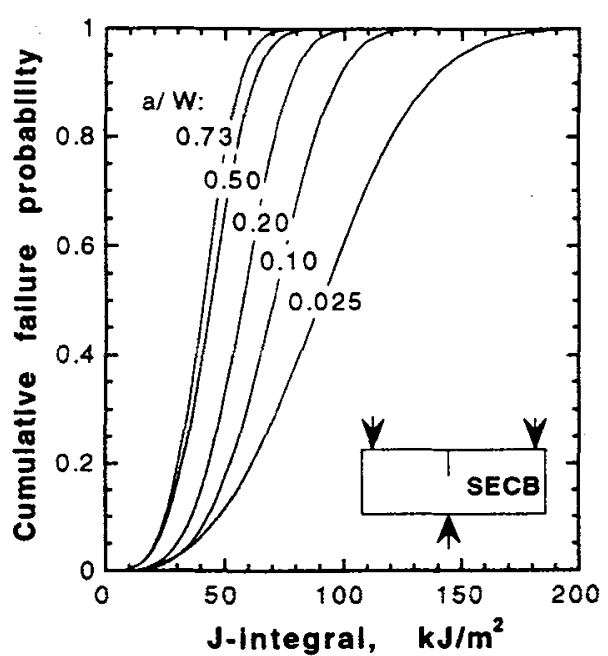

Figure 10: Variation of cumulative failure probability with applied $\mathbf{J}$ for three-point bend specimens with crack length to specimen with ratio in the range $0.025<\mathrm{a} / \mathrm{w}<0.73$

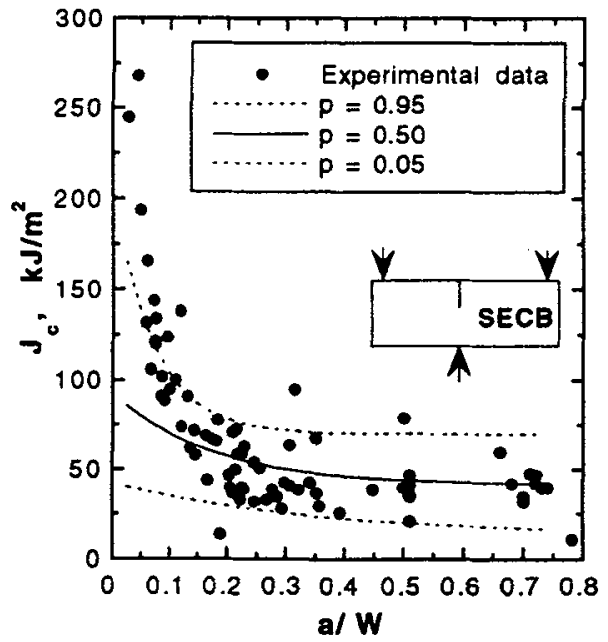

Figure 11 : Comparison of experimental and predicted variation in cleavage toughness with a/W. BS4360 43A mild steel, $\mathrm{T}=-50^{\circ} \mathrm{C}$ 